\title{
L-Arabinose and D-Xylose Catabolism in Aspergillus niger
}

\author{
By C. F. B. WITTEVEEN, ${ }^{1}$ R. BUSINK, ${ }^{1}$ P. VAN DE VONDERVOORT, \\ C. DIJKEMA, ${ }^{2}$ K. SWART ${ }^{1}$ AND J. VISSER ${ }^{1 *}$ \\ Departments of Genetics ${ }^{1}$ and Molecular Physics, ${ }^{2}$ Agricultural University, Dreyenlaan 2, \\ 6703 HA Wageningen, The Netherlands
}

(Received 18 January 1989; revised 3 May 1989; accepted 10 May 1989)

\begin{abstract}
A mutant of Aspergillus niger unable to grow on D-xylose and L-arabinose has been isolated. Genetic analysis revealed that the mutation is located on linkage group IV. Enzymic analysis revealed a deficiency in D-xylulose kinase activity. After transfer of growing mycelium to a medium containing either D-xylose or L-arabinose, the mutant accumulates large amounts of arabitol and xylitol, as shown by ${ }^{13} \mathrm{C}$ NMR spectroscopy. These data and an analysis of enzyme activities induced by $\mathrm{D}$-xylose and L-arabinose in the wild-type strain led to the following catabolic pathway for D-xylose: D-xylose - xylitol - D-xylulose - D-xylulose 5-phosphate; and for L-arabinose : L-arabinose - L-arabitol - L-xylulose - xylitol - D-xylulose - D-xylulose 5-phosphate. The reduction steps of the sugars to the corresponding polyols are all NADPH dependent. The oxidation steps of the polyols to the sugars are all $\mathrm{NAD}^{+}$dependent. Fractionation of cell-free extracts gave information about the specificity of the enzymes and showed that all the reactions are catalysed by different enzymes.
\end{abstract}

\section{INTRODUCTION}

Pentose metabolism in filamentous fungi has received little attention since the early reports on this subject by Chiang and coworkers (Chiang et al., 1958; Chiang \& Knight, 1959, 1960a, $b$, 1961). Later, Hankinson (1974) studied, in Aspergillus nidulans, two classes of mutants, pppA and $p p p \mathrm{~B}$, which were disturbed in the pentose phosphate pathway. These mutants showed no or decreased growth on D-xylose and L-arabinose. D-Xylose metabolism has been studied intensively in yeasts, especially in relation to the production of ethanol under anaerobic conditions (Jeffries, 1985). L-Arabinose catabolism, however, has received little attention.

Most organisms convert both D-xylose and L-arabinose to D-xylulose 5-phosphate, although different pathways are used by different organisms. A remarkable difference between bacteria and most fungi is the way in which they convert D-xylose to D-xylulose. Bacteria usually use an isomerase, whereas fungi reduce $D$-xylose to xylitol which is subsequently oxidized to D-xylulose (Jeffries, 1983). For L-arabinose breakdown several pathways have been described. The reduction-oxidation pathway described for Penicillium chrysogenum by Chiang \& Knight (1961) contains the following steps: an NADPH-dependent reduction to L-arabitol, oxidation to Lxylulose $\left(\mathrm{NAD}^{+}\right)$, reduction to xylitol (NADPH) and oxidation to D-xylulose $\left(\mathrm{NAD}^{+}\right)$. The principle of this catabolic sequence is comparable to the $D$-xylose pathway found in fungi (Chiang \& Knight, 1960b).

Aspergillus niger grows well on pentose substrates and it can also hydrolyse polymers, such as hemicellulose, which contain these sugars. Pentoses are presumably important substrates for this fungus, and since for Aspergillus little information is available on this subject, this study on catabolism of L-arabinose and D-xylose was initiated.

Biochemicals. The pent(ul)oses, pentitols and D-xylulose-5-phosphate were purchased from Sigma. NAD(P) ${ }^{+}$, NAD(P)H, ATP, glucose 6-phosphate, 6-phosphogluconate, phosphoenolpyruvate and enzymes were supplied by 
Boehringer Mannheim. Other chemicals were from Merck. Sephadex G25 and the Mono Q column were obtained from Pharmacia. Matrex Red A was from Amicon.

Isolation of the mutant and genetic mapping of the mutation. The parental strain used in this investigation was an auxotrophic and morphological mutant, N423, derived from Aspergillus niger N400 (CBS-120-49). The markers of mutant N423 are short conidiophores (cspAl) and a nicotinamide deficiency (nic A1) (Bos et al., 1988).

Further mutations were induced by UV treatment of strain N423. A suspension of conidia $\left(10^{7} \mathrm{ml}^{-1}\right)$ in a Petri dish was irradiated for $2 \mathrm{~min}$ with $2 \mu \mathrm{J} \mathrm{mm}^{-2} \mathrm{~s}^{-1}$, resulting in $93 \%$ survival (Bos, 1987). A filtration enrichment procedure was employed, essentially as described by Uitzetter $e$ t al. (1986), using $10 \mathrm{ml}$ of the irradiated conidia and $40 \mathrm{ml}$ minimal medium, with xylitol as carbon source and supplemented with nicotinamide $\left(1 \mathrm{mg} \mathrm{l}^{-1}\right)$. The conidial suspension was incubated at $30^{\circ} \mathrm{C}$ in a rotary shaker. The filtration and refreshment of the medium was carried out twice a day and the enrichment procedure was continued over $96 \mathrm{~h}$, after which time $3 \times 10^{4}$ conidia were left. The conidia were rescued on complete medium with glucose as carbon source and grown for $48 \mathrm{~h}$ at $30^{\circ} \mathrm{C}$. The colonies obtained were tested on minimal medium supplemented with nicotinamide and different carbon sources: glucose, gluconic acid, acetic acid, D-xylose and L-arabinose. Mutants which showed defective growth on xylose were purified for further analyses.

The linkage group of the mutation was determined by somatic recombination with a tester strain (N655; Bos et al., 1988) carrying a colour marker and auxotrophic markers on different linkage groups, viz. fwnAl (I); his D4 (II); lysA7, bioAl (III); leuAl (IV); met $\mathrm{B} 1$ (V); pabAl (VI). Isolation of diploids and haploidization was performed according to Bos et al. (1988). Segregants were analysed for genetic markers and the linkage of the mutation with the markers of the tester strain was determined.

Media and growth conditions. Minimal medium contains, per litre: $1.5 \mathrm{~g} \mathrm{KH}_{2} \mathrm{PO}_{4}, 0.5 \mathrm{~g} \mathrm{KCl}, 0.5 \mathrm{~g}$ $\mathrm{MgSO}_{4} .7 \mathrm{H}_{2} \mathrm{O}, 2.1 \mathrm{~g}$ urea, $0.1 \mathrm{~g}$ yeast extract, $0.9 \mathrm{mg} \mathrm{ZnSO}{ }_{4} .7 \mathrm{H}_{2} \mathrm{O}, 0.2 \mathrm{mg} \mathrm{MnCl} 2.4 \mathrm{H}_{2} \mathrm{O}, 0.06 \mathrm{mg} \mathrm{CoCl}_{2} .6 \mathrm{H}_{2} \mathrm{O}$, $0.06 \mathrm{mg} \mathrm{CuSO} \mathrm{C}_{4} .5 \mathrm{H}_{2} \mathrm{O}, 0.04 \mathrm{mg}\left(\mathrm{NH}_{4}\right)_{6} \mathrm{Mo}_{7} \mathrm{O}_{24} .4 \mathrm{H}_{2} \mathrm{O}, 0.29 \mathrm{mg} \mathrm{CaCl} 2.2 \mathrm{H}_{2} \mathrm{O}, 0.2 \mathrm{mg} \mathrm{FeSO}{ }_{4} .7 \mathrm{H}_{2} \mathrm{O}$, and $1 \mathrm{mg}$ nicotinamide. The carbon source was $20 \mathrm{~g}$ sucrose $\mathrm{I}^{-1}$ or $100 \mathrm{mM}$-D-xylose, L-arabinose or D-glucose; these were added separately as membrane-filter-sterilized solutions.

Conidiospores were harvested from complete medium according to Pontecorvo et al. (1953) except that glucose was replaced by $2 \%(w / v)$ sucrose.

Mycelium was grown in Erlenmeyer flasks containing $300 \mathrm{ml}$ medium and incubated in a New Brunswick rotary shaker for $24 \mathrm{~h}$ at 280 r.p.m. and $30^{\circ} \mathrm{C}$.

To permit measurements of pentose-catabolism-related enzyme activities in the pentose mutant N572, this strain was grown on minimal medium with sucrose for about $24 \mathrm{~h}$ and subsequently transferred to minimal medium containing either L-arabinose or D-xylose for $16 \mathrm{~h}$ to induce the pentose-catabolism-related activities. The same procedure was used to grow mycelium for the NMR measurements.

Growth tests were performed on Petri dishes containing minimal medium, $1.5 \%(\mathrm{w} / \mathrm{v})$ agar and $50 \mathrm{~mm}$ of one of the carbon sources.

Preparation of mycelium for NMR measurements. NMR sample preparation and NMR measurements were done as previously described (Dijkema et al., 1985).

Preparation of cell-free extracts. Mycelium was harvested by filtration, washed with $0.85 \% \mathrm{NaCl}$ and frozen in liquid nitrogen. The frozen mycelium was disrupted in a Braun dismembrator and subsequently suspended in extraction buffer ( $20 \mathrm{mM}$-Bis-Tris pH 6.5, $5 \mathrm{mM} \mathrm{MgCl}, 1 \mathrm{mM}$ - $\beta$-mercaptoethanol). After $1 \mathrm{~h}$ the homogenate was centrifuged at $10000 \mathrm{~g}$ for $10 \mathrm{~min}$. Low-molecular-mass compounds were removed from the supernatant by passage through a $15 \mathrm{ml}$ Sephadex G25 column. This preparation was used for enzyme assays and fractionation experiments.

Fractionation of cell-free extract. A $1 \mathrm{ml}$ portion of cell-free extract purified over a Sephadex G25 column was fractionated on a FPLC Mono $\mathrm{Q}$ column using a gradient of $0-0.5 \mathrm{M}-\mathrm{NaCl}$ in $20 \mathrm{mM}-\mathrm{Bis}-\mathrm{Tris} \mathrm{pH} 6.5,5 \mathrm{mM}-\mathrm{MgCl}_{2}$ and $1 \mathrm{mM}-\beta$-mercaptoethanol.

Enzyme assays. Enzyme activities were measured at $25^{\circ} \mathrm{C}$ on an Aminco DW-2 spectrophotometer in the dualwavelength mode, measuring $A_{340}-A_{380}$. A value of $5.33 \mathrm{~mm}^{-1} \mathrm{~cm}^{-1}$ was used for the absorption coefficient of NAD(P)H.

Enzyme assays were performed in a $1 \mathrm{ml}$ volume. The assay mixtures for the enzymes were as follows. Pentitol dehydrogenases - 100 mM-glycine buffer $\mathrm{pH} 9.6,0.4 \mathrm{mM}-\mathrm{NAD}(\mathrm{P})^{+}, 100 \mathrm{mM}$-xylitol, L-arabitol, D-arabitol or ribitol; pentose reductases (EC 1.1.1.21) - $50 \mathrm{~mm}$-sodium phosphate buffer $\mathrm{pH}$ 6.5, $0.2 \mathrm{mM}-\mathrm{NAD}(\mathrm{P}) \mathrm{H}, 100 \mathrm{mM}$ $\mathrm{L}$-arabinose or D-xylose; pentulose reductases were assayed as the pentose reductases with $5 \mathrm{mM}-\mathrm{D}$-xylulose, L-

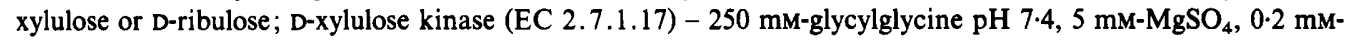
$\mathrm{NADH}, 1$ unit pyruvate kinase, 3 units lactate dehydrogenase, $1.5 \mathrm{mM}$-phosphoenolpyruvate, $5 \mathrm{mM}$-D-xylulose, 1 mM-ATP. Glucose-6-phosphate dehydrogenase (EC 1.1.1.49), 6-phosphogluconate dehydrogenase (EC 1.1.1.44) and fructose-1,6-bisphosphatase (EC 3.1.3.11) were measured as described by Bruinenberg et al. (1983b). DXylulose-5-phosphate phosphoketolase (EC 4.1.2.9) was measured by the two methods described by Evans \& Ratledge (1984). D-Xylose isomerase (EC 5.3.1.5) was determined as described by Callens et al. (1986). 
Table 1. Enzyme activities involved in pentose metabolism in A. niger

A niger N423 (parental strain) was grown for $21 \mathrm{~h}$ on D-glucose, L-arabinose or D-xylose (each $100 \mathrm{~mm}$ ) as carbon source. Activities are expressed in $\mathrm{nmol} \mathrm{min} \mathrm{m}^{-1}$ (mg protein) $)^{-1}$.

\begin{tabular}{|c|c|c|c|c|}
\hline & & & Specific activity & \\
\hline Enzyme & Cofactor & D-Glucose & $\begin{array}{l}\text { Carbon source: } \\
\text { L-Arabinose }\end{array}$ & D-Xylose \\
\hline D-Xylose reductase & NADH & 0 & 0 & 0 \\
\hline & NADPH & 10 & 245 & 934 \\
\hline L-Arabinose reductase & NADH & 0 & 0 & 0 \\
\hline & NADPH & 26 & 619 & 786 \\
\hline D-Ribose reductase & NADH & 0 & 0 & 0 \\
\hline & NADPH & 5 & 142 & 516 \\
\hline D-Arabinose reductase & NADH & 0 & 0 & 0 \\
\hline & NADPH & 4 & 3 & 12 \\
\hline L-Xylulose reductase & NADH & 5 & 240 & 49 \\
\hline & NADPH & 22 & 287 & 71 \\
\hline D-Xylulose reductase & NADH & 31 & 1137 & 700 \\
\hline & NADPH & 14 & 67 & 53 \\
\hline D-Ribulose reductase & NADH & 21 & 365 & 114 \\
\hline & NADPH & 60 & 72 & 78 \\
\hline Xylitol dehydrogenase & $\mathrm{NAD}^{+}$ & 21 & 852 & 494 \\
\hline & $\mathrm{NADP}^{+}$ & 8 & 118 & 40 \\
\hline D-Arabitol dehydrogenase & $\mathrm{NAD}^{+}$ & 12 & 15 & 8 \\
\hline & NADP+ & 18 & 19 & 23 \\
\hline L-Arabitol dehydrogenase & $\mathrm{NAD}^{+}$ & 6 & 279 & 68 \\
\hline & $\mathrm{NADP}^{+}$ & 0 & 16 & 16 \\
\hline Ribitol dehydrogenase & $\mathrm{NAD}^{+}$ & 14 & 583 & 274 \\
\hline & $\mathrm{NADP}^{+}$ & 3 & 12 & 10 \\
\hline D-Xylulose kinase* & & 0 & 430 & 230 \\
\hline
\end{tabular}

To enable measurement of $D$-xylulose kinase in crude cell free extract we either fractionated the mycelium on an FPLC Mono Q column (for analysis of the mutant) or partially purified the extract by passing $1 \mathrm{ml}$ over a $0.3 \mathrm{ml}$ Matrex Red A affinity column, which resulted in removal of most of the D-xylulose reductase activity, thus enabling the kinase assay to be performed. The last method was used for the data shown in Table 1.

Analytical methods. Protein concentration was estimated, after denaturation and precipitation of protein with sodium deoxycholate and trichloroacetic acid (Bensadoun \& Weinstein, 1976), by the microbiuret method (Itzhaki \& Gill, 1964), using bovine serum albumin as standard.

\section{RESULTS}

\section{Isolation and mapping of the mutant}

After the filtration enrichment 420 colonies were rescued. Screening of these colonies revealed only three mutants: one pentose-negative mutant (N572) and two auxotrophic mutants. The mutation in the pentose-negative mutant is denoted $x k i \mathrm{Al}$.

Upon haploidization of a diploid obtained from a heterokaryon of N572 and N655, 130 segregants were analysed. The frequency of recombination between $x k i \mathrm{~A} 1$ and leuAl was $20.0 \%$, whereas this frequency with all the other markers varied between $45 \%$ and $60 \%$. Therefore the $x k i \mathrm{Al}$ mutation is located on linkage group IV. The recombination between markers known to be located on one linkage group was $10.0 \%$ for bioAl and lys 7 (linkage group III) and $5.4 \%$ for nic A1 and met $\mathrm{B} 1$ (linkage group V). These data demonstrate the high frequency of mitotic recombination in $A$. niger relative to $A$. nidulans.

\section{Growth characteristics}

The growth of strain $\mathrm{N} 423$ and the pentose mutant $\mathrm{N} 572$ on a range of carbon sources was compared. The mutant did not grow at all on $\mathrm{D}$-xylose, $\mathrm{L}$-arabinose or xylitol; the slight growth 
which $A$. niger normally shows on agar medium without carbon source is prevented in the mutant by these compounds. The parental strain grew well on these three substrates. On the other pentoses and pentitols tested (D-arabinose, D-ribose, L-arabitol, D-arabitol and ribitol), the parental strain grew weakly, and the mutant very weakly. Thus the effect of the mutation on growth was more severe on good substrates. The $x k i$ A mutant grew normally on substrates other than pentoses (D-glucose, acetate, D-gluconate, D-galacturonate, D-glucuronate, meso-inositol). The utilization of nitrogen sources, including nitrate, was the same in the mutant and the parental strain.

\section{Polyol accumulation in the xkiAl mutant and its parent}

Information on the in vivo effect of a mutation can be derived from the accumulation patterns of metabolites. In vivo ${ }^{13} \mathrm{C}$ NMR spectroscopy is a useful tool for such measurements. We used this technique to study metabolite accumulation in the parental strain N423 and the pentose mutant N572, both grown for $24 \mathrm{~h}$ on minimal medium with sucrose and subsequently transferred for $16 \mathrm{~h}$ to minimal medium with $\mathrm{D}$-xylose or L-arabinose. The results are shown in Fig. 1. Only that part of the spectrum in which the polyol resonances are visible is shown. The resonance positions of erythritol, mannitol and arabitol are as described by Dijkema et al. (1985); xylitol shows resonances at $63.6(\mathrm{C} 1$ and $\mathrm{C} 5), 71.9(\mathrm{C} 3)$ and $72.9(\mathrm{C} 2$ and $\mathrm{C} 4)$ p.p.m. The $24 \mathrm{~h}$ cultures of both strains grown on sucrose showed the usual metabolite accumulation pattern for $A$. niger, namely high levels of mannitol and erythritol. Growth of N572 on sucrose is normal and no difference between the mutant and the parent was seen in these spectra (Fig. 1, A and B). Transfer of these sucrose-grown mycelia to media containing D-xylose or L-arabinose followed by $16 \mathrm{~h}$ incubation resulted in large differences between parent and mutant. On D-xylose the parent accumulated, in comparable amounts, the same polyols as observed on sucrose (Fig. 1, C). Transfer to L-arabinose resulted in accumulation of arabitol and xylitol as well as mannitol and erythritol (Fig. 1, E). The erythritol resonances coincide with two of the xylitol resonances. Integration of the spectrum showed that the relative amounts of arabitol and xylitol were approximately $3: 1$. Transfer of mutant mycelium to either D-xylose or L-arabinose resulted in accumulation of about equal amounts of arabitol and xylitol (Fig. 1, D and F). The polyols mannitol and erythritol had been metabolized by the mycelium because no external carbon source was available. The strong similarity between the mutant spectra on L-arabinose and D-xylose indicates a connection between the two catabolic pathways prior to the step affected by the mutation. Since it is impossible to discriminate between L-arabitol and D-arabitol with ${ }^{13} \mathrm{C}$ NMR we do not know which isomer of arabitol is accumulated in the mycelium.

\section{Determination of D-xylulose kinase deficiency}

In crude cell-free extracts it was impossible to measure D-xylulose kinase activity with the pyruvate kinase/lactate dehydrogenase coupled assay because of high NADH-dependent Dxylulose reductase and ATPase activities. These interfering activities were separated from the kinase activity by fractionation of the cell-free extract on an FPLC Mono Q column. The elution of the D-xylulose kinase activity from the column is shown in Fig. 2(a). At the position where in N423 extracts D-xylulose kinase eluted, only a residual activity ( $<5 \%$ of the parental value) was found in extracts of N572. Other enzyme activities of the pentose catabolic pathway were found at normal or even higher levels in mutant mycelium compared to induced parental mycelium (data not shown). Thus induction of the pathway did take place in the mutant with the procedure we used. In all other fractions no D-xylulose kinase activity was found (data not shown). This proves that $\mathrm{N} 572$ is a D-xylulose kinase mutant.

\section{Induction of enzymes specific to the D-xylose and L-arabinose pathways}

We measured the activities of a number of relevant enzymes to establish the catabolic pathways which $\boldsymbol{A}$. niger utilizes to degrade pentoses. In addition, the activities of glucose-6phosphate dehydrogenase, 6-phosphogluconate dehydrogenase and fructose-1,6-bisphosphatase were measured to see whether the hexose monophosphate pathway is involved in the regeneration of NADPH needed for the pentose reduction. 


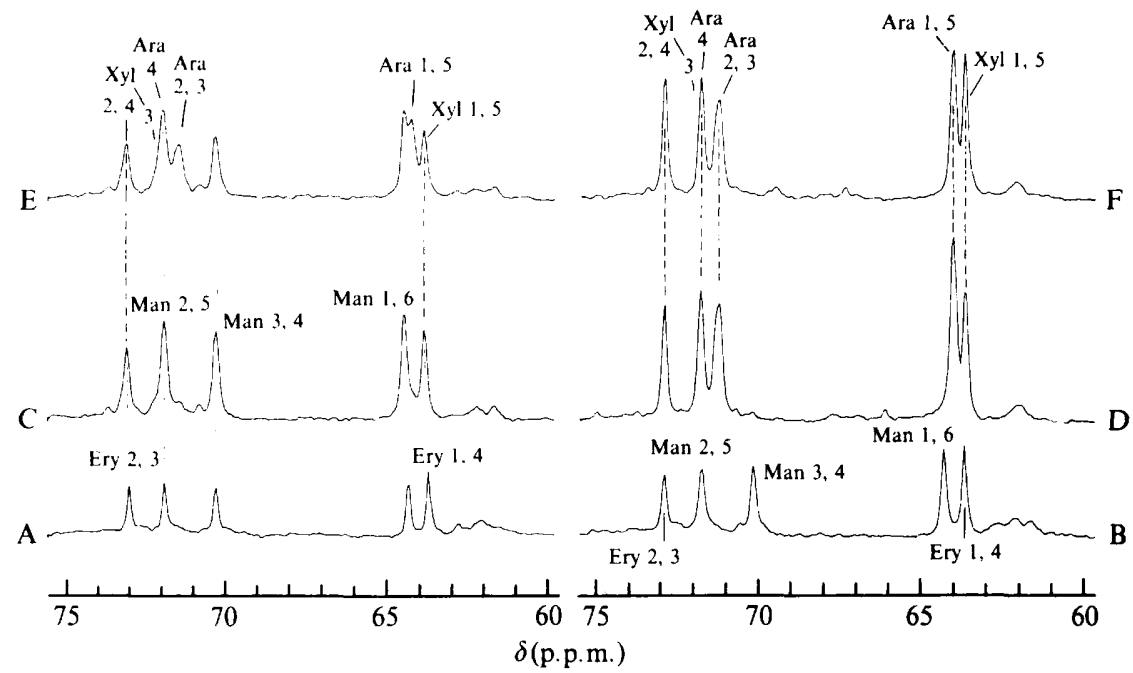

Fig. 1. Natural-abundance ${ }^{13} \mathrm{C}$ NMR spectra of the polyol resonance region of $A$. niger $\mathrm{N} 423$ (parental strain ; spectra A, C and E) and N572 (xkiAl mutant; spectra B, D and F). A, B, spectra taken after $24 \mathrm{~h}$ growth on $50 \mathrm{~mm}$-sucrose; C, D, spectra $16 \mathrm{~h}$ after transfer to D-xylose $(0.1 \mathrm{M}) ; \mathrm{E}, \mathrm{F}$, spectra $16 \mathrm{~h}$ after transfer to L-arabinose $(0 \cdot 1 \mathrm{M})$.

The pentose-related enzyme activities (Table 1) were found to be dependent on the age of the mycelium, showing a gradual decrease with time. However, the relative values were comparable. The activities for $\mathrm{D}$-xylulose kinase could not be determined accurately. The partial purification on a Matrex Red A column may have caused some loss of activity, and the high background activities, even after partial purification, decreased the precision of the measurement.

In agreement with the catabolic pathway described for Penicillium chrysogenum by Chiang \& Knight (1961), growth of $A$. niger on D-xylose induced D-xylose reductase (NADPH), xylitol dehydrogenase $\left(\mathrm{NAD}^{+}\right)$and $\mathrm{D}$-xylulose kinase, while growth on L-arabinose induced Larabinose reductase (NADPH), L-arabitol dehydrogenase $\left(\mathrm{NAD}^{+}\right)$, L-xylulose reductase (NADPH), xylitol dehydrogenase $\left(\mathrm{NAD}^{+}\right.$) and D-xylulose kinase (Table 1). However, besides these expected activities we measured a few activities which are not involved in the catabolic pathway described by Chiang \& Knight (1961). In the first place, relatively large amounts of $\mathrm{NAD}^{+}$-dependent ribitol dehydrogenase and D-ribulose reductase were found, especially in L-arabinose-grown mycelium. To find out whether this was due to lack of specificity of one of the enzymes or to induction of other enzymes, we fractionated a cell free extract of $L$-arabinosegrown mycelium (Fig. $2 b$ ). A protein binding weakly to the Mono Q column contained NAD ${ }^{+}$ dependent xylitol and ribitol dehydrogenase activity (relative activity of xylitol :ribitol $1: 0 \cdot 43$ ). The second activity peak showed $\mathrm{NAD}^{+}$-dependent L-arabitol, xylitol and ribitol dehydrogenase activity $(1: 0 \cdot 35: 0 \cdot 8$, respectively). NADH-dependent L-xylulose and D-xylulose reduction was measured in this second activity peak. The first activity was also found in Dxylose-grown mycelium, whereas the second could only be measured in L-arabinose-grown mycelium. These data prove that the high ribitol dehydrogenase activity is due to lack of specificity of both the L-arabitol and xylitol dehydrogenases.

A second observation that needs further explanation is the induction of D-ribose reductase and L-arabinose reductase on D-xylose and the induction of D-ribose reductase and D-xylose reductase on L-arabinose (Table 1). These data suggest that there are at least two enzymes involved which might have a broad substrate spectrum. To investigate the properties of pentose reductases in D-xylose- and L-arabinose-grown mycelium we separated the activities on a FPLC Mono Q column (Fig. 3). The results show that two different enzymes exist which elute very close to each other. The first is induced in particular by D-xylose and is relatively nonspecific. From these and other data we estimated a relative activity for this general pentose reductase 


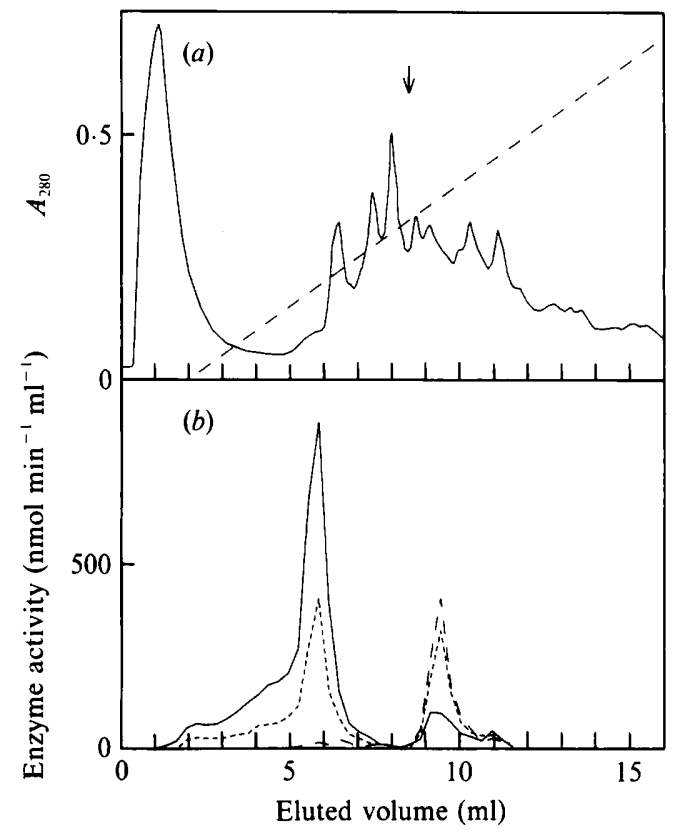

Fig. 2

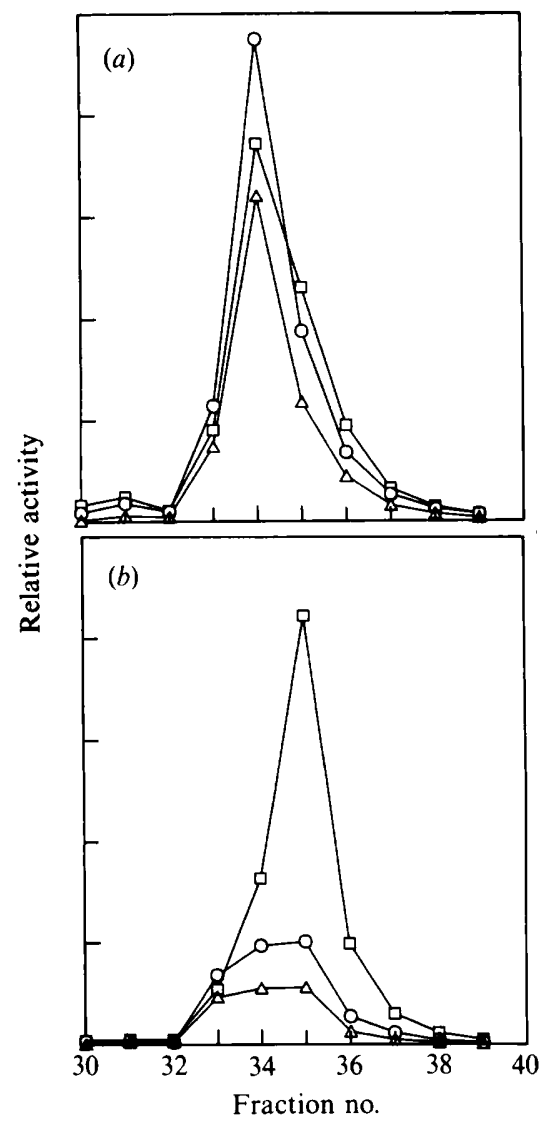

Fig. 3

Fig. 2. Fractionation by FPLC Mono Q chromatography of cell-free extract of $A$. niger $\mathrm{N} 423$ grown on L-arabinose. (a) Absorption at $280 \mathrm{~nm}$ of column eluate. The applied salt gradient $(0-0.5 \mathrm{M}-\mathrm{NaCl}$ in 20 mM-Bis-Tris pH 6.5) is indicated (--). The elution position of the D-xylulose kinase activity is indicated by the arrow. (b) Activity profile of $\mathrm{NAD}^{+}$-dependent pentitol dehydrogenase, upon fractionation. — - Xylitol dehydrogenase; ---, ribitol dehydrogenase; _- - , L-arabitol dehydrogenase.

Fig. 3. NADPH-dependent pentose reductase activities in cell-free extracts of $A$. niger N423 grown on D-xylose $(a)$ and L-arabinose $(b)$ fractionated by FPLC Mono Q column chromatography. Fractions of $0.3 \mathrm{ml}$ were collected and assayed for the following enzyme activities: $\bigcirc$, D-xylose reductase; $\square$, L-arabinose reductase; $\triangle$, D-ribose reductase.

towards D-xylose, L-arabinose and D-ribose of $1: 0 \cdot 78: 0 \cdot 66$, respectively. This enzyme is also found in L-arabinose-grown mycelium, together with an L-arabinose reductase with a relatively high specificity towards L-arabinose. The relative activity of this latter enzyme towards Dxylose, L-arabinose and D-ribose was estimated to be $0 \cdot 2: 1: 0 \cdot 1$, respectively. In later stages of growth on L-arabinose the activity of the general pentose reductase increased relative to the Larabinose reductase, giving about equal activities of both enzymes (data not shown). We have subsequently purified another L-arabinose-pathway-specific enzyme, the NADPH-dependent L-xylulose reductase. This enzyme is quite specific towards L-xylulose as substrate and is only induced by L-arabinose. The detailed results will be published elsewhere.

We conclude from the data presented here that all the steps in the two catabolic pathways are catalysed by different enzymes. We were not able to measure significant amounts of D-xylose isomerase, the enzyme catalysing the isomerization reaction between D-xylose and D-xylulose.

Especially for growth on L-arabinose, large amounts of NADPH are required. We expected therefore that growth on L-arabinose would require increased activity of the pentose phosphate 
Table 2. Enzyme activities in A. niger N423 grown for 21 h on $100 \mathrm{~mm}$ D-glucose, L-arabinose or $\mathrm{D}-x y$ lose with urea as nitrogen source

Activities are in $\mathrm{nmol} \mathrm{min}^{-1}$ (mg protein) ${ }^{-1}$.

$\begin{array}{lccc}\text { Enzyme } & \overbrace{\text { D-Glucose }} & \begin{array}{c}\text { Carbon source: } \\ \text { L-Arabinose }\end{array} & \text { D-Xylose } \\ \text { Glucose-6-phosphate dehydrogenase } & 436 & 928 & 839 \\ \text { 6-Phosphogluconate dehydrogenase } & 103 & 185 & 236 \\ \text { Fructose-1,6-bisphosphatase } & 12 & 9 & 17\end{array}$

pathway. To test this hypothesis we measured fructose-1,6-bisphosphatase, glucose-6-phosphate dehydrogenase and 6-phosphogluconate dehydrogenase activities (Table 2). The activities of the two dehydrogenases were much higher in mycelia grown on the two pentoses relative to glucose, suggesting an increased flux through the hexose monophosphate pathway.

Finally we investigated whether D-xylulose-5-phosphate phosphoketolase was present, which would be able to convert xylulose 5-phosphate, in a phosphoroclastic reaction, into acetylphosphate and glyceraldehyde 3-phosphate. We were not able to measure significant amounts of this enzyme. This makes it very likely that only the non-oxidative pentose phosphate pathway is involved in D-xylulose 5-phosphate conversion.

\section{DISCUSSION}

The mutant N572 is only defective in growth on pentoses or pentitols. Its growth is normal on other substrates, including those which are most probably catabolized by pathways which lead to the pentose phosphate pathway; this is regardless of the nitrogen source used. This indicates that the mutant is defective in a pentose-specific pathway rather than in the pentose phosphate pathway like the mutants described by Hankinson (1974).

Chiang and coworkers proposed for Penicillium chrysogenum a series of reduction and oxidation steps for the conversion of L-arabinose and D-xylose to D-xylulose, which is subsequently phosphorylated to D-xylulose 5-phosphate (Chiang \& Knight, 1959, 1961). The phenotype of the mutant $\mathrm{N} 572$, the ${ }^{13} \mathrm{C}$ NMR data and the enzyme activity measurements show that this pathway is also used by $A$. niger.

Chiang \& Knight (1961) assumed that D-xylose and L-arabinose are reduced by a single NADPH-dependent enzyme and also that L-arabitol and xylitol oxidation is catalysed by a single enzyme. Our data clearly show that this is not the case in $A$. niger. Every catabolic step is catalysed by a separate enzyme, although some of the enzymes show a broad substrate specificity and may, in part, take over each other's function. For example, the general pentose reductase, the enzyme catalysing $\mathrm{D}$-xylose reduction, also has a high L-arabinose reductase activity and is present in large amounts during growth on L-arabinose, especially in the later stages.

The induction of the dehydrogenases of the pathway and the lack of xylose isomerase activity confirm the assumption that the isomerase reaction does not play a role in most fungi (Jeffries, 1983). Considering all the metabolic intermediates involved, one can conclude that all the enzymes necessary for growth on D-xylose are also involved in L-arabinose catabolism. However, the reverse is not true. This has some implications for the kind of mutants one might expect to find, using the filtration enrichment method as we did. A mutant growing on Larabinose and not growing on D-xylose cannot be obtained. Our method to isolate a mutant unable to grow on xylitol logically resulted in the isolation of a D-xylulose kinase mutant. The other possibility, a xylitol dehydrogenase mutant, is not likely to be found, since the conversion of xylitol to D-xylulose is also catalysed by L-arabitol dehydrogenase. This activity is probably sufficient to enable some growth and prevent selection by the filtration enrichment method. The 
strong correlation between the two catabolic pathways has already been described by Barnett (1976), who studied the growth of a large number of yeasts on several substrates.

There are a few other examples in the literature of fungal mutants in D-xylose metabolism. Maleszka et al. (1983) described a xylitol dehydrogenase mutant in Pachysolen tannophilus, unable to grown on D-xylose and xylitol. This proves that in this organism no isomerase is involved. McCracken \& Gong (1983) isolated a number of mutants in a Candida sp. with abnormal product formation from D-xylose. One mutant, showing higher D-xylose conversion, lower xylitol formation and increased ethanol production under aerobic conditions, was characterized more extensively. Higher levels of xylitol dehydrogenase and D-xylulose kinase were found in this mutant. This is an indication that the xylitol dehydrogenase and D-xylulose kinase levels are rate-limiting in the parental strain.

Since the reduction steps all use NADPH and the oxidation steps $\mathrm{NAD}^{+}$as cofactor there is a large need for NADPH, especially during growth on L-arabinose. Calculations by Bruinenberg et al. (1983a) of the total need of the yeast cell for NADPH on different substrates illustrate this very well. The induction of both glucose-6-phosphate dehydrogenase and 6-phosphogluconate dehydrogenase by growth on pentoses (Table 2) suggests that the oxidative pentose phosphate pathway supplies this NADPH as it does in yeast (Bruinenberg et al., 1983b).

For the final conversion of D-xylulose 5-phosphate there are two possibilities. The first is formation of fructose 6-phosphate and glyceraldehyde 3-phosphate by the enzymes of the nonoxidative pentose phosphate pathway. The second is phosphoketolase-catalysed conversion to acetylphosphate and glyceraldehyde 3-phosphate. The latter reaction is known to occur in, for example, Lactobacillus plantarum (Heath et al., 1958) and is claimed to play an important role in some yeasts (Evans \& Ratledge, 1984). We were not able, however, to detect significant phosphoketolase activity. Therefore the most likely pathway in $A$. niger is the pentose phosphate pathway.

The sequence of four alternating reduction and oxidation steps in L-arabinose catabolism with the thermodynamic equilibrium far in the direction of the polyols is potentially a rate-limiting factor in the catabolic sequence. The fact that the pentitols of the pathway are visible in the ${ }^{13} \mathrm{C}$ NMR spectra of wild-type mycelium grown on L-arabinose confirms that a considerable accumulation of arabitol, in particular, is necessary to obtain a forward flux. The cofactor use of the enzymes involved stimulates the flux in the direction of D-xylulose, assuming that the anabolic reduction charge $[\mathrm{ARC}=\mathrm{NADPH} /(\mathrm{NADP}++\mathrm{NADPH})]$ is larger than the catabolic reduction charge $\left[\mathrm{CRC}=\mathrm{NADH} /\left(\mathrm{NAD}^{+}+\mathrm{NADH}\right)\right]$. It is not possible to determine the real cofactor levels in the cytoplasm because different compartments are present and unknown proportions of the pyridine nucleotides are bound to enzymes. However, total concentrations have been measured in several organisms and these results are in agreement with the above statement (Führer et al., 1980; Voordouw et al., 1983; Gancedo \& Gancedo, 1973; Sáez \& Lagunas, 1976). The values measured for $A$. niger as determined by Führer et al. (1980) are $\mathrm{ARC}=0.37$ and $\mathrm{CRC}=0 \cdot 1$. Apart from consequences due to the specific cofactor use as discussed above, the extra-high level of the D-xylulose kinase in L-arabinose-grown mycelium (Table 1) would stimulate the flux through the pathway as well.

This research was supported by The Netherlands Technology Foundation (STW), Utrecht grant no. WBI 47.0637 and by the Agricultural University Biotechnology Program on Biocatalysts.

\section{REFERENCES}

BARnetT, J. A. (1976). The utilization of sugars by yeasts. Advances in Carbohydrate Chemistry and Biochemistry 32, 125-228.

Bensadoun, A. \& Weinstein, D. (1976). Assay of proteins in the presence of interfering materials. Analytical Biochemistry 70, 241-250.

Bos, C. J. (1987). Induction and isolation of mutants in fungi at low mutagen doses. Current Genetics 12, 471474.
Bos, C. J., Debets, A. J. M., Swart, K., Huybers, A., Kobus, G. \& Slakhorst, S. M. (1988). Genetic analysis and the construction of master strains for assignment of genes to six linkage groups in Aspergillus niger. Current Genetics 14, 437-443.

Bruinenberg, P. M., van Dijken, J. P., Scheffers, W. A. $(1983 a)$. A theoretical analysis of NADPH production and consumption in yeasts. Journal of General Microbiology 129, 953-964. 
Bruinenberg, P. M., van Dijken, J. P. \& Scheffers, W. A. $(1983 b)$. An enzymic analysis of NADPH production and consumption in Candida utilis. Journal of General Microbiology 129, 965-971.

Callens, M., Kesters-Hilderson, H., van Opstal, O. \& DE BRUYNE, C. K. (1986). Catalytic properties of D-xylose isomerase from Streptomyces violaceoruber. Enzyme and Microbial Technology 8, 696-700.

Chiang, C. \& Knight, S. G. (1959). D-Xylose metabolism by cell-free extracts of Penicillium chrysogenum. Biochimica et biophysica acta 35, 454-463.

Chiang, C. \& Knight, S. G. (1960a). A new pathway of pentose metabolism. Biochemical and Biophysical Research Communications 3, 554-559.

Chiang, C. \& KNight, S. G. $(1960 b)$. Metabolism of D-xylose by moulds. Nature, London 188, 79-81.

Chiang, C. \& KNIGHT, S. G. (1961). L-Arabinose metabolism by cell-free extracts of Penicillium chrysogenum. Biochimica et biophysica acta 46, 271-278.

Chiang, C., Sih, C. J. \& Knight, S. G. (1958). The conversion of D-xylose to xylitol by Penicillium chrysogenum. Biochimica et biophysica acta 29, 664-665.

Dijkema, C., Kester, H. C. M. \& Visser, J. (1985). Carbon-13 NMR studies of carbon metabolism in the hyphal fungus Aspergillus nidulans. Proceedings of the National Academy of Sciences of the United States of America 82, 14-18.

Evans, C. T. \& Ratledge, C. (1984). Induction of xylulose-5-phosphate phosphoketolase in a variety of yeasts grown on D-xylose: the key to efficient D-xylose metabolism. Archives of Microbiology 139, 48-52.

FÜHRER, L., KubiceK, C. P. \& RoHR, M. (1980). Pyridine nucleotide levels and ratios in Aspergillus niger. Canadian Journal of Microbiology 26, 405-408.

GANCEDO, J. M. \& GANCEDO, C. (1973). Concentrations of intermediary metabolites in yeast. Biochimie 55, 205-211.

Hankinson, O. (1974). Mutants of the pentose phosphate pathway in Aspergillus nidulans. Journal of Bacteriology 117, 1121-1130.
Heath, E. C., Hurwitz, J., Horecker, B. L. \& GinsberG, A. (1958). Pentose fermentation by Lactobacillus plantarum. I. The cleavage of xylulose5-phosphate by phosphoketolase. Journal of Biological Chemistry 231, 1009-1029.

ITZHAKI, R. F. \& GILL, O. M. (1964). A microbiuret method for estimating proteins. Analytical Biochemistry 9, 401-410.

JEFFRIES, T. W. (1983). Utilization of xylose by bacteria, yeasts, and fungi. Advances in Biochemical Engineering and Biotechnology 27, 1-32.

JEFFRIES, T. W. (1985). Emerging technology for fermenting D-xylose. Trends in Biotechnology 3 , 206-221.

Maleszka, R., Neirinck, L. G., James, A. P., RutTen, H. \& SCHNEIDER, H. (1983). Xylitol dehydrogenase mutants of Pachysolen tannophilus and the role of xylitol in D-xylose catabolism. FEMS Microbiology Letters 17, 227-229.

McCracken, L. D. \& Gong, C. S. (1983). D-Xylose metabolism by mutant strains of Candida sp. Advances in Biochemical Engineering and Biotechnology 27, 33-55.

Pontecorvo, G., Roper, J. A., Hemmons, L. M., MacDonald, K. D. \& Bufton, A. W. J. (1953). The genetics of Aspergillus nidulans. Advances in Genetics 5, 141-239.

SÁEz, M. J. \& Lagunas, R. (1976). Determination of intermediary metabolites in yeast. Critical examination of the effect of sampling conditions and recommendations for obtaining true levels. Molecular and Cellular Biochemistry 13, 73-78.

Uitzetter, J. H. A., Bos, C. J. \& Visser, J. (1986). Characterization of Aspergillus nidulans mutants in carbon metabolism isolated after D-galacturonate enrichment. Journal of General Microbiology 132, 1167-1172.

Voordouw, G., Van der Vies, S. M. \& Themmen, A. P. N. (1983). Why are two different types of pyridine nucleotide transhydrogenase found in living organisms? European Journal of Biochemistry 131 $527-533$. 